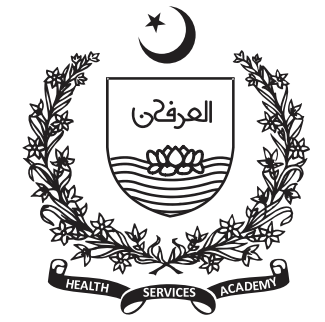

${ }^{1}$ Center for South Asian Studies, University of the Punjab, Lahore, Pakistan

2Project Officer, AntiNarcotics Force, Punjab

Corresponding Author:

Maria Ali

Email:

maria.ali@foundationfyr.com

\section{Increasing Trend of Substance Using among Females of Punjab}

\author{
Maria Ali ${ }^{1,2}$, Naheed. S. Goraya ${ }^{1}$
}

\section{Abstract}

The article gives a detailed study of facts and figures of female substance users in Punjab as reported in different surveys. It discusses the major reasons of increasing trend of substance using among females of Punjab out of which the most prominent roots of this menace are discussed in this review as socioeconomical pressure and the role of entertainment and social media. Common social factors were found to be peer pressure and relational substance use among females. Financially, most of the women started using substance as a result of transition from housewife to caretakers of family. Some students were addicted to substance using from friends already addicted to substance use while other students started abusing substance due to stress of hectic study routines. In some reported cases, young ones were encouraged to use substance by watching an elder substance user. Transition from chars to other substances of choice was also found in many female substance users. Case studies of some Female Substance Users expressed some awful and serious issues which need immediate attention. There is a large risk factor associated with this increasing trend of substance using in this region which needs to be tackled carefully by the government and certain other non-governmental bodies.

Key Words: Female Substance Users, women, monetary supplier, injecting

\section{Introduction}

A A Policeman in Lahore revealed that new and dangerous form substances abuse has been growing to a large extent in the youth of Punjab especially in major cities like Lahore, Multan and Faisalabad. Developing nation like Pakistan is confronting this deadly issue for the recent few decades and despite various mishaps and lethal occasions, still, this issue isn't as expected examined or dealt with. Indeed, even the quantity of substance users is expanding at an alarming rate. From the recent couple of years, research uncovered that the quantity of substance users is expanding enormously quick and the gender which is popping up is female. Indeed, young girls, understudies and married women are involved in this revile and are utilizing these illicit substances nowadays. College-going girls from upper-middle class with extra pocket money are involved in this menace to the society. The substances used vary from heroin, cocaine, speed, to liquor.

This new challenge adds to the previous issue of abuse of conventional substances like "Charas" in huge areas of Punjab. To this day, bureaucratic and public government has not had the option to concoct an approach to handle these issues. The arrangement lies neither willfully ignorant of a circumstance that exists for quite a long time nor in responding with unjustifiable caution.

The path forward lies in understanding and thinking of a thoroughly examined legal reaction. Regularly known as garda or hash (among the more rich), the utilization of charas goes back millennia in Punjab. However the subject of its utilization and history is strictly taboo in the society and infrequently referenced in the media. Charas utilization may not be straightforwardly recognized however the entire endeavor of development, assembling, dispersion, and 
offer of the cannabis item has developed into a profoundly productive and modern industry over the decades.

Students in our nation are confronting serious educational issues that need immediate attention to save their future and the future of the forthcoming generation. It was reported in an article that out of 15 substance user students, 11 students had started using drugs before entering university (1). It is reflecting towards our defective educational framework that isn't working as expected, subsequently pouring all burdens on students. Pakistan has consistently been confronted with substance misuse issues since the time its independence and today. Indo-Pak was once the legal maker and purchaser of opium and different medications. Authorized shops were making a chain of substance dealers at that time. Pakistan has been the biggest heroin purchaser in south-Asia locale. In Asia, where the substance dealing has been at its pinnacle, Pakistan was the most exceeding victim of it.

Talking about the history of substance abuse in Pakistan, Pakistan has consistently faced with a substance misuse issue since the time of its independence to the day. The nation has the biggest heroin shopper market in the south-west Asia area. While the whole locale experiences the substance trade in South Asia, Pakistan seems, by all accounts, to be its most exceedingly terrible victim.

Opium and poppy have consistently been developed in the Northern part of Pakistan. Opium has been sold in authorized shops in this region for decades before independence. After freedom in 1947, similar laws were trailed by the public authority until 1979, when the "Hadood' law was passed. The statute set a restriction on the development, creation, dealing and utilization of opiates inside Pakistan, which prompted the shutting down of legitimate source for substance, day by day, illicit accessibility of substances proceeded. It was not until right Pakistan turned into a significant exporter of heroin during the 1980s, following a massive deluge of Afghan displaced people in 1979. The significant result of this has been a critical expansion in homegrown utilization of heroin in Pakistan. As an extent of substance victimizers, heroin clients expanded from 7.5 percent in 1983 to a stunning 51 percent in 1993 (United Nations Office on Drugs and Crimes UNODC 2010).

From that point forward Heroin use has arrived at scourge extents in Pakistan influencing practically every financial community. In the same way as other human issues, the issue of substance misuse contacts the most vulnerable: most of substance clients in Pakistan have a place with the most unfortunate layers of society. According to a news report in 2016 about 700 people used to die every day due to substance related complications in Pakistan (2).

\section{Different impact of Substance use on Women}

Though, addictive issues have been the subject of far and wide concern, moderately little is thought about the causes, treatment, and avoidance of these issues in women. While substance misuse is all the more frequently announced by men and examination to date has zeroed in chiefly on male substances clients and victimizers, substance misuse has by and large been considered as an issue of men. In many developed nations, substance misuse in any case, is not, at this point an only or then again prevalently male action. Generally, male and female substance use patterns appear to be all the more even in developed nations. There is, in any case, barely any data on abuse among women from developing nations, where official information proposes that substance use references are solely a male wonder. There is growing proof that it gives the idea that there is a general expansion in the quantities of women utilizing substances globally. One of the central points which favor the increment of substance use among women is the progress of women from the customary parts of mother and homemaker to that of a monetary supplier for the family. Though, this can be viewed as a positive addition it can likewise force more prominent degrees of stress, and substance use is a potential reaction without other ways of dealing with stress.

As per said by an addiction psychiatrist Dr. Kristen Schmidt of Hazelden Betty Ford Foundation in an interview, women are biologically, environmentally and psychologically different from men and so do the outcomes if we do not consider these facts. Biologically, women have Estrogen hormone not present in men and studies have shown that females have increased intake of substances than men (3). Another study showed that females will increase intake of alcohols and if concentration of alcohol is increased male will start to titrate off the alcohol use while female will continue to use. Mostly when women come to treatment and rehab centers of substance use, they have more severe addictions than men and women also have less of the enzyme that breaks down the alcohol. Thus there is a huge physiological fact to be considered in substance 
using among females. Environmentally, most of the women tend to be relational substance users. A study showed that $50 \%$ of female heroin users were $1^{\text {st }}$ time ever injected was from a male partner or friend(4). In most developing places like the major cities of Punjab mentioned earlier, women are caretakers of families and often times they need to support their family. In some reported cases, women used to take meth to get extra energy for exhaustive field work and household chores and became addictive to it.

According to a journal published by Eastern Mediterranean Regional Office of World Health Organization, $43 \%$ spouses of male IDUs had been active sexually with their substance using partner, and also $4 \%$ of them reported selling sex. $23 \%$ used substances and 19\% used injecting substances(5).

In a report issued by The Nation in 2018, 20\% of total substance users in Pakistan were women and women were found more averse to getting drug treatment(6).

\section{Categories of Substances used by Women}

Different categories of illicit substances are being used by various strata of the society depending on level of addiction and financial stability. Following types of substances have most commonly been used in this region of Pakistan for decades.

\section{Alcohol}

Alcohol has been a most common and conventional substance used for centuries globally. It is a sort of drink and thus is taken orally. Most of the students start it as fashion and take it usually by mixing it with cold drinks like coca cola and sprite or also with water. When they become addicted to it they start taking it in pure form and end in serious medical conditions. In cities, it is being used as fashion in different bachelor parties and night parties where addicted people having privileges avail it. In most cases, the minors avail alcohol from their friends and in some cases minors have also availed alcohol from their elders. Most women working as sex sellers or dancers for money are found addictive to alcohol. This trend has been much common in the marriage ceremonies in the villages of south Punjab and is still growing fast in spite of extended policies of law making bodies. Most landlords in Punjabi villages show off their money by arranging such parties and involving in such illicit activities. Their women are also involved in these activities to some extent. A form of alcohol named 'desi sharab' is made in locals of Punjab villages and is used their in large quantities and is also traded to the other parts of the region. According to research in 2010, alcohol abuse is the third leading cause of death in the USA, making almost $3.5 \%$ of the total deaths each year(7).

\section{Tobacco}

Tobacco is abundantly produced and used in the world. In Pakistan, it is used commonly in Hukkahs and cigarettes. Its control dose is used in many medicines for treatments. But its abuse can cause serious health issues. Though not considered in substances, it can be very addictive and in the case of uncontrolled use, it poses serious health risks. The wide availability of Hukkahs has created a misconception in people that it is not harmful. Hukkahs are also considered as fashion and are very common even in many sophisticated families. There have been different alternatives to Hukkah like electrical vapes which use chemical vaporizers smoked with electric sparks. The flavors used in these electrical vapes are also found to be very dangerous. It contains nicotine, small amounts of which are so addictive. It activates the brain's reward system which evokes pleasurable desires like eating and sexual pleasure. Males and females are equally involved in smoking different forms of tobacco. Smoking cigarettes has also led to smoking chars and using other substances in many cases. It is spreading at an alarming rate in very young students of primary and secondary schools. Although it is illegal to smoke below 18, neither the sellers of cigarettes and Hukkahs care nor do the law enforcement bodies. Due to our culture, $80 \%$ to $90 \%$ of adult smokers began from adolescence and then become regular smokers before 18 years of their age. Due to tobacco abuse liver and lung diseases are showing up on the scene very fast.(8)

\section{Marijuana}

Marijuana is a substance that is collected from the cannabis plant. Most commonly it is smoked in cigarette-like papers, sniffed and sometimes taken orally. Its effects depend on the ways it is consumed. It contains mind-altering ingredients that greatly affect mental abilities. Its effects include the feeling of happiness, mild hallucinations, increased appetite, reduce anxiety. It has a very strong addiction ability which not only makes a person addicted to itself but also to urges to take an even more powerful substance. According to a survey report by United Nations Office on Substances and Crimes (UNODC) held in Pakistan reported that the category of substances which is most commonly being taken by female substance users is Chars(9). 
A high or uncontrolled dose of marijuana can cause permanent effects on brains functionality and ultimately death.

\section{Ice}

The most potent of the above is crystal methamphetamine or commonly known as ice. It is the recently growing substance in the region of Punjab and is spreading very widely at tremendous rates. It is a synthetic substance and is very active central nervous system stimulant substance. It is taken in different ways usually smoked in bongs, sniffed in the powdered form, injected or taken orally. Its intake causes the release of neurotransmitters norepinephrine, serotonin and dopamine and also blocks the re-uptake of these neurotransmitters thus producing the intense feelings of pleasure and excitement.

Reported in news, a young female addict was taken into custody by police in Hayatabad, who was later handed over to the Social Welfare Department officials for rehabilitation and treatment. The woman was one of the numerous female addicts seen in various roads and public spots in the provincial capital (10). This says a lot about the increment being used of ice, heroin, hashish and different medications by the ladies, in Peshawar as well as numerous parts of the country. Furthermore, more youngsters including understudies of colleges, universities and those living in hostels are turning out to be substance addicts. There would be not many women utilizing heroin or different substances up to this point. Notwithstanding, the utilization among the females expanded over the most recent couple of years. Several years back, a little youngster in her midtwenties was discovered dead in the fields of the Pawaka town in rural Peshawar. While examining the occurrence, police tracked down the young lady was an ice (meth or methamphetamine) addict who was seen by numerous individuals in the city roads while searching for the substances. A few ladies can be seen on public spots in the cities like Lahore devouring substances. A source educated that the utilization regarding ice is accepted to have arrived at a disturbing level, particularly among the adolescent, understudies and ladies. There are numerous examples of deaths brought about by its misuse. A source educated that a Peshawar inhabitant supposedly executed his wife under effect of ice when she was sleeping in her room a few years ago. The source said that the accessibility of ice, heroin and hashish in Peshawar and different locale of KP has gotten very simple. He added that one gram of ice costs anyplace somewhere in the range of Rs2,000 and Rs10,000, contingent upon the quality and different factors however the young is getting more addictive to the medication for the last numerous years. Specialists accepted that a portion of ice may trigger in excess of 1,200 units of dopamine which is $600 \%$ more than what the body can do all alone. Ceaseless utilization of ice influences the body and abbreviates life by numerous years. Ice can be handily produced and can be devoured orally, through infusions or breathed in. One portion of ice is 3.5 occasions more extreme than cocaine. An authority of the Peshawar police said a forceful activity has been dispatched against the street pharmacists, especially those associated with deal and dealing of ice and heroin. The authority said countless sellers were captured while numerous addicts were shipped off the restoration habitats over the most recent few weeks. Moves were additionally made in area of different instructive organizations and inns.

Some major factors which are causing this increase in female substance addiction can be briefed out as follow;

\section{Family Pressure}

Female substance addicts mostly have preliminary family pressure which includes financial instability, relational substance use i.e. having a substance addict spouse, father or brother and sudden transition from housewife to caretaker due to certain reasons like cheating, death or divorce from their hubby. These reasons induce substance addictions in lower class of the society and the families working on daily wages as shown in the above case studies of three girls.(11)

\section{Role of social media and entertainment media}

Most of the female substance users of this category belonged to upper middle-class families having extra money. In such community, the role of media has been tremendous in advancing the utilization of illicit substances, tobacco and liquor among particularly young people who get controlled by these Advertisements effectively and are invoked to check out. When attempted, it slowly turns into a habit and turns out to be extremely hard for them to stop. Aside from advertisements, films particularly R-rated enormously affect the life of people. They watch their favorite celebrities utilize unlawful substances, tobacco and alcohols, getting them more acquainted with these and end up taking them. Aside from all these the Internet and the Social media has proved to influence the life of their users adversely. People frequently will see intense advertisements in social apps like Facebook, 
Instagram etc. seeing which our brains get attracted by these despite the fact that we would prefer not to. Additionally, apps like Google and Facebook have created algorithms to provide more personalized advertisements to their particular clients depending on the information accessible to them. The ads shown generally are more explicit to what the client needs really. This may bring about effectively intensifying the interest of the people who are now into it. Furthermore, this may additionally make harder for them to stop those habits.(12)

\section{Easy Access to Drug Dealers}

The basic reason for the consistent teenage and bachelors substances use has always been the ease in the access to different substances. In cities there is a well arranged chain of substance suppliers and dealers which makes the substance abuse very easy for students especially those living in the hostels, flats and rented houses or those who are living alone or with their male friends in their houses. Even university students have been found to be involved in these illicit activities of substance dealing and substance abuse. Any other student which comes into their company becomes vulnerable to substance abuse and can become a substance addict. There are found some cases in which the graduated female students who lived in the hostels and became substance addicts, when came back to their homes after completing their education they used to live alone without quenching the thirst of their addiction and in most cases they would involve in intimate relation with multiple male substance users for the sake of substance availability.(13)

\section{Literature Review}

University World News was informed by Amra Raza, the director of Pakistan Studies Center at Punjab University, Lahore that it was an important concern for the government and the governing bodies of universities. Awareness-raising, Strict watch-and-ward regimes, and curriculum alterations shell be enacted in the premises of universities and the government must act to disrupt the wide accessibility of substances to the university students.

Shahriyar Afridi, the interior minister of Pakistan has confessed that a relatively large number of students are taking substances in order to enhance their mental abilities.

United Nations Office on Substance and Crime conducted a survey in Pakistan in 2006. In this survey, detailed research was conducted, finding people who were involved in substance abuse and were addicted to it. The main objectives of this research were to highlight the total information on board. Also, this was aimed to highlight the importance of this issue for the government to take action on it and create awareness campaigns on it, to aware people of how lethal and destructive culture it is and why it is important to eradicate this deadly lifestyle. The main course of this detailed survey and research was subjected to discuss female substance users in Pakistan and how it can affect society and its norms. The increasing trend of substance use can be seen from reports that in 2012 about 6.7 million people were substance users in Pakistan as reported by UNODC (2013) and this number grew to 9 million in 2018 as reported by Pamir Times (Drug Abuse in Pakistan, 2018)(14).

According to the report, out of 4,632 female substance users, 593 were from Lahore, 511 from Faisalabad, 285 from Multan, 282 from Sargodha, and 198 were from DG Khan. The survey indicated the highest number of female substance users in Karachi but out of all other cities, the major cities of Punjab like Lahore, Multan, Faisalabad and Okara showed considerable number of female substance users(9).

These interviews revealed that the major substance of choice among female substance users was Marijuana (Chars) reportedly $28 \%$ as compared to Bhang $(14.2 \%)$, Heroin (13.6\%) and Pharmaceutical Substances (12.6\%). Karachi showed complicated distribution of substances types showing that all substances of concern were in use their but the capital of Punjab i.e. Lahore showed the highest number of Chars using females.

It can be noteworthy that the injecting substance use was not found common in female substance users(5). In Lahore, out of 593 Female Substance Users, only 12 were Injecting Substance Users. Survey also concluded that the most common substances used in Injections were Pharmaceutical Substances comprising 53.5\% of total Female Injecting Substance Users.

A study on heroin addiction in Pakistan revealed that the Alcohol drinking and Marijuana use was higher in the groups below 20 years and Heroin use was more frequent in the age group of 21-40 years. In this study, out of total study subjects $64 \%$ were from Punjab(15).

The substance abuse was also found very common in students of medical colleges. In a survey held in medical colleges of Lahore, about $21 \%$ of total subjects (52\% female subjects) were substance users(16). Other 
studies also revealed that there were certain institutional factors due to which students were involved in substance abuse(17). The involvement of teachers in substance abuse encouraged the substance user students(18).

In another survey held by UNODC in association with Ministry of Interior and Narcotic Control Pakistan in 2013, in Punjab out of estimated 61.41 million people having age between 15 and 64 years $4.7 \%$ or 2.9 million people had used any substance in the preceding year. According to this report, out of 6.7 million substance users in Pakistan one quarter i.e. 1.5 million were women. An astonishing outcome was that 39.8\% regular opiate users were not working at that time and $35.7 \%$ opiate users were only working casually(19).

The health risks associated with substance using among females have also been considerable(20). According to a report, 22\% male Injecting Drug Users(IDUs) had sexual intercourse out of which only $7 \%$ always used condoms thus posing a high risk of spreading contagious diseases and STDs in females specially when they involved multiple persons(21). According to the report by Chris P Archibald, the overall HIV prevalence in Pakistan increased from 16.2\% in 2006 to $31.0 \%$ in $2011(22)$.

In a survey held in Lahore, $52.5 \%$ of total Injecting Substance Users were married and up to $7 \%$ were separated after marriage thus affecting their related women e.g. spouses and daughters in many ways(23). According to another report, $35 \%$ of total male Intravenous substance users in Lahore were married with $42 \% \mathrm{HCV}, 35 \% \mathrm{HBV}$ and $10 \% \mathrm{HCV}$ infection seroprevalence(24).

There are given case studies of some female substance users reported by UNODC Pakistan whose study could be helpful to conclude the major factors causing this exponential growth in the number of Female Substance Users in Punjab (the most populous province of Pakistan). These are given as below;

Nasreen was a teenager girl living with her father, mother and brother. Her father was a substance addict and he used to bring his friends along with him at home. Her mother used to work in different houses to bear the expenses and she used to take care of his mentally retarded brother at home. One day her father sold her to a person for the sake of substances. She was 17 years old and was raped by that person. From that day she started smoking followed by Heroin and other injecting substances. She lives with her unwanted child in streets. Although she is a substance user, she hopes for a good future of his child and is desirous of sending him to a school.

Rabia, a 16 years old girl struggling to financially stabilize her family used to work as a nurse in a private clinic. Due to financial and social issues, she started getting stressed out. A friend of her introduced her with a psychotic substance medicine to relieve stress. She started taking that substance without the recommendations of doctor. She started to take them more often as she felt relaxed with those pills. At the end she started taking substances and became a substance addict. She started losing her physical and mental capabilities. Later, her mother got hospitalized due to a serious illness and she thought of quitting substances for the sake of her family. She contacted UNODC and requested for their help. She was then helped by UNODC and her body was properly detoxified.

Saira a 33 years old woman was single parent of two children. Her hubby cheated on her and left her. She became financially unstable. She applied for jobs at various platforms but was rejected from all of them. The reason was defected job channeling system. Due to financial and social stress she started taking some relaxing pills. Gradually she shifted to substances. Now she is in an awful condition waiting for someone's help.

\section{Conclusion}

Considerable numbers of female substance users were spread in all strata of society. Most prominent classes were the lower and lower middle classes who used substances due to different sorts of social pressures while the second most prominent class of female substance users was upper middle class due to lack of awareness. In most of the cases they started using substances from some already addicted male or female friends. When we see some facts and figures of different surveys, we come to know that most Female substance users started smoking Chars in the beginning and then transitioned to other substances like crystal methamphetamine. The use of substances in female was not limited to universities and cities. A large portion was also found to be substance addict in different villages of Punjab. To tackle this menace the basic issues like financial instability, certain social norms and unawareness and also the economic gap between upper middle class and lower class needs to be addressed. 


\section{References}

1. Alexopoulos EC, Jelastopulu E, Aronis K, Dougenis DJEh, medicine $\mathrm{p}$. Cigarette smoking among university students in Greece: a comparison between medical and other students. 2010;15(2):115-20.

2. Qasim M. Drug addiction kills 700 people every day in Pakistan: The News; June 27,2018 [Available from: https://www.thenews.com.pk/print/130881-Drugaddiction-kills-700-people-every-day-in-Pakistan.

3. Brady KT, Randall CLJPCoNA. Gender differences in substance use disorders. 1999;22(2):241-52.

4. McElrath K, Harris JJJoSU. Peer injecting: implications for injecting order and blood-borne viruses among men and women who inject heroin. 2013;18(1):31-45.

5. Ahmad S, Mehmood J, Awan AB, Zafar ST, Khoshnood K, Khan AAJE-EMHJ, 17 , 271-276,. Female spouses of injection drug users in Pakistan: a bridge population of the HIV epidemic? 2011.

6. Asghar S. Drug abuse in Pakistan reaches alarming level: The Nation; February 10, 2018 [Available from: https://nation.com.pk/10-Feb-2018/drug-abuse-inpakistan-reaches-alarming-level.

7. Liu SW, Lien MH, Fenske NAJCid. The effects of alcohol and drug abuse on the skin. 2010;28(4):391-9.

8. Martins-Green M, Adhami N, Frankos M, Valdez M, Goodwin B, Lyubovitsky J, et al. Cigarette smoke toxins deposited on surfaces: implications for human health. 2014;9(1):e86391.

9. Assessment B. Female Drug Use in Pakistan. 2010.

10. Khan JA. More women, youth addicted to ice drug: The News; January 20, 2021 [Available from: https://www.thenews.com.pk/print/776916-morewomen-youth-addicted-to-ice-drug.

11. Lal R, Deb KS, Kedia SJIjop. Substance use in women: Current status and future directions. 2015;57(Suppl 2):S275.

12. Romer D, Moreno MJP. Digital media and risks for adolescent substance abuse and problematic gambling. 2017;140(Supplement 2):S102-S6.
13. Marangoni SR, Oliveira MLFdJT, Contexto-Enfermagem. Triggering factors for drug abuse in women. 2013;22:66270.

14. Ali M. Drug Abuse in Pakistan: Pamir Times; December 2, 2018 [Available from: https:/ / pamirtimes.net/2018/12/02/drug-abuse-inpakistan-2/.

15. Ghazal PJPh. Rising trend of substance abuse in Pakistan: a study of sociodemographic profiles of patients admitted to rehabilitation centres. 2019;167:34-7.

16. Noshad M, Butt MH, Mehboob T, Bashir I, Aslam R, Tabassam NJP. Psychoactive substances abuse trends among medical students of lahore; a cross sectional study. 2020;70(6):1935-40.

17. Owolabi OO, Adelabu OA, Oyelana AAJJoS, Anthropology S. Alcoholism and Drug Abuse in Higher Institutions of Learning. 2016;7(3):132-43.

18. Sajid MA, Tatlah IA, Butt IH. Causes of drug abuse among university students in pakistan: Variation by gender and drug type. 2020.

19. Yaqub FJTL. Pakistan's drug problem. 2013;381(9884):2153-4.

20. Kilpatrick DG, Acierno R, Resnick HS, Saunders BE, Best CLJJoc, psychology c. A 2-year longitudinal analysis of the relationships between violent assault and substance use in women. 1997;65(5):834.

21. Parviz S, Fatmi Z, Altaf A, McCormick JB, Fischer-Hoch $\mathrm{S}$, Rahbar M, et al. Background demographics and risk behaviors of injecting drug users in Karachi, Pakistan. 2006;10(5):364-71.

22. Archibald CP, Shaw SY, Emmanuel F, Otho S, Reza T, Altaf A, et al. Geographical and temporal variation of injection drug users in Pakistan. 2013;89(Suppl 2):ii18ii28.

23. Emmanuel F, Attarad AJJ-PMA. Correlates of injection use of synthetic drugs among drug users in Pakistan: a case controlled study. 2006;56(3):119.

24. Rasool SH, Arif M, Ahmed MJPJMHS. Sociodemograhic profile of intravenous drug users in Lahore-a retrospective study. 2014;8:338-43. 